\title{
FORMAÇÃO INICIAL DE SOLDADOS DA POLÍCIA MILITAR DO ESTADO DO RIO DE JANEIRO NO CONTEXTO DA REFORMA GERENCIAL DO ESTADO ${ }^{2}$
}

\author{
Célia Cristina Pereira da Silva Veiga ${ }^{3}$ \\ José dos Santos Souza ${ }^{4}$
}

\begin{abstract}
Resumo
O objeto de investigação deste artigo é o Curso de Formação de Soldados (CFSd) da Polícia Militar do Estado do Rio de Janeiro (PMERJ), condicionado pelas mudanças na política de segurança pública a partir da reforma gerencial do Estado. O objetivo do texto é explicitar contradições existentes na configuração do CFSd determinadas pela atual política de segurança pública. Os resultados da pesquisa permitem afirmar que as mudanças ocorridas na política de segurança pública, a partir da Reforma do Estado, sofisticaram o discurso de mediação do conflito de classes propondo modelos de policiamento pautado na concepção de polícia cidadã, embora a formação dos policiais da PMERJ continue pautada na coerção.
\end{abstract}

Palavras-chave: Reforma do Estado; política de segurança pública; formação policial militar.

\begin{abstract}
The object of investigation of this article is the Training Course of Soldiers (TCSd) by Polícia Militar do Estado do Rio de Janeiro (PMERJ), determined by the current configuration of the public security policy from the managerial reform of State. The objective of this paper is to explain contradictions in the TCSd determined by the current configuration of the public security policy. The results of the research allow us to affirm that the changes occurred in the public security policy, in the state's

\footnotetext{
${ }^{1}$ DOI: https://doi.org/10.22409/tn.16i29.p4557

2 Esta é uma versão revisada do trabalho originalmente intitulado"Aspectos políticos e pedagógicos da formação inicial de soldados e suas interfaces com a política de segurança pública no Rio de Janeiro",apresentado no GT-09 Trabalho e Educação da XXXVIII Reunião da Associação Nacional de Pesquisa e Pós-Graduação em Educação, ocorrida de 01 a 05 de outubro de 2017, em São Luiz (MA).

${ }^{3}$ Licenciada em Pedagogia pela UFRRJ; Mestre em Educação pela UFRRJ; Doutoranda em Educação pelo Programa de Pós-Graduação em Educação, Contextos Contemporâneos e Demandas Populares (PPGEDUC) da Universidade Federal Rural do Rio de Janeiro (UFRRJ). Atua como Professora Substituta do Departamento de Educação e Sociedade do Instituto Multidisciplinar da UFRRJ. É membro do Grupo de Pesquisas Sobre Trabalho, Política e Sociedade (GTPS), e-mail: celiacveiga@gmail.com.

${ }^{4}$ Doutor em Sociologia pelo Instituto de Filosofia e Ciências Humanas (IFCH) da Universidade Estadual de Campinas (UNICAMP), com Pós-Doutorado em Educação pela Faculdade de Educação da UNICAMP. Atua como Professor Associado do Departamento de Educação e Sociedade do Instituto Multidisciplinar da Universidade Federal Rural do Rio de Janeiro (UFRRJ), onde integra o quadro docente do Programa de Pós-Graduação em Educação, Contextos Contemporâneos e Demandas Populares (PPGEduc). É líder do Grupo de Pesquisas sobre Trabalho, Política e Sociedade (GTPS). E-mail: jsantos@ufrrj.br
}

TrabalhoNecessário- www.uff.br/revistatrabalhonecessario: ano 16, №29/2018 
reform context, sophisticated the discourse of mediation of class conflict, proposing models of policing based on the conception of citizen police, although police training of PMERJ continues based on the coercive model.

Keywords: State reform; Public security policy; Military police training.

\section{Introdução}

A reforma do Estado desencadeada pela crise do capital, a partir da década de 1970, provocou alterações nas ações e nas concepções da política de segurança pública. Nesse contexto, organismos multilaterais e financeiros internacionais influenciaram na proposição de alterações da política de segurança no país sob a perspectiva gerencial. Alterações essas demonstradas nas diretrizes da atual política de segurança pública que vem sendo adotada no estado do Rio de Janeiro.

A partir deste contexto, tomamos como objeto de investigação a política pedagógica do Curso de Formação de Soldados (CFSd) da Polícia Militar do Estado do Rio de Janeiro (PMERJ). Nosso objetivo é explicitar as interfaces entre as ações e formulações no campo da política de segurança pública e a política pedagógica do CFSd. Trata-se de uma pesquisa básica, de análise qualitativa, de caráter explicativo, que se insere na categoria de uma pesquisa documental, embora se utilize de entrevistas semiestruturadas com gestores da educação profissional da PMERJ e questionários aplicados a 983 policiais militares que concluíram o CFSd, a fim de aprofundamento da análise.

Neste trabalho, sistematizamos análises dos resultados da pesquisa que nos permitem afirmar que as mudanças ocorridas na política de segurança pública a partir das investidas do Bloco no Poder para empreender a Reforma do Estado e reorientar o uso do fundo público sofisticaram o discurso e as práticas para mediação do conflito de classes, propondo modelos de policiamento baseados na predominância de estratégias de persuasão e convencimento, embora a política pedagógica aplicada no CFSd continue pautada na coerção e na violência, onde o controle social é obtido por meio da repressão armada. A análise empreendida aponta que a propagação do ideário gerencialista na gestão da política de segurança pública condiciona significativamente a formação inicial dos soldados, o que faz emergir limites e contradições. 
Neste sentido, o texto desenvolve a abordagem do tema a partir de três seções: uma, que trata da reforma do Estado e da propagação do ideário gerencialista; outra, que trata das interferências da reforma gerencial na política de segurança; e a terceira, que trata da forma como essas mudanças na política de segurança pública, decorrentes da reforma gerencial, se materializam nas ações e nas formulações da PMERJ para a formação inicial de seus soldados.

\section{Reforma do Estado, Gerencialismo e Segurança Pública}

A crise estrutural do capital, desencadeada a partir da década de 1970 , foi impulsionada pelo esgotamento das bases de acumulação do modelo fordista e a crise do modelo keynesiano, o que levou à recomposição burguesa para retomada das bases de acumulação corroídas pela crise estrutural instalada (Cf.: HOBSBAWN, 1977; HARVEY, 2007; SOUZA, 2015). Tal recomposição

configurou-se em duas frentes de ação: o desenvolvimento do regime de acumulação flexível e a reforma do Estado para reorientar o uso do fundo público (SOUZA, 2016a). Como uma dimensão da reforma do Estado, a ofensiva ética e moral ao modo de regulação social keynesiano ganhou materialidade na crítica ferrenha à burocratização do serviço público e na apologia a uma Nova Gestão Pública, mais flexível, enxuta, pautada em resultados e nos princípios da accountability.

A reforma administrativa empreendida no serviço público é composta por estratégias tais como: apologia à lógica mercantil, combate ao modelo de bemestar social, racionalização e cortes orçamentários, privatização, parcerias público-privadas e reforma gerencial (SOUZA, 2016a). Esse processo tem como base o ideário neoliberal com a mediação da Terceira Via. Seu propósito central é reorientar o uso do fundo público para garantir a estabilidade do grande capital, sobretudo porque o Estado é agente institucional orientado pelas instituições financeiras internacionais (CHOMSKY, 1999).

Bresser-Pereira (1997), um dos idealizadores da reforma do Estado no Brasil, relatou que o Banco Mundial e o Banco Interamericano de Desenvolvimento (BID) facilitaram empréstimos para promoção da reforma do Estado e a Organização das Nações Unidas (ONU) promoveu assembleia geral para tratar de administração pública, o que desencadeou ajustes no papel do

TrabalhoNecessário- www.uff.br/revistatrabalhonecessario: ano 16, №29/2018 
Estado e na sua relação com a sociedade civil, em vários países. No Brasil, esse processo de reforma foi iniciado com a eleição de Fernando Collor de Melo, em 1989, embora tenha sido em meados da década de 1990, no início do Governo Fernando Henrique Cardoso, que esta reforma ganhou contornos mais evidentes. Um marco desse processo foi a criação do Ministério da Administração e Reforma de Estado (MARE) (BRASIL, 1995), capitaneado por Luís Carlos Bresser Pereira, um dos fundadores do Partido da Social Democracia Brasileira (PSDB).

Ressaltamos que a ideologia capitalista que sustenta o consentimento ativo das massas à reforma do Estado é o gerencialismo. O termo gerencialismo, hoje, significa a proposição de um jeito mais flexível e pretensamente menos burocrático de gerenciar o serviço público. Considerando que gerenciar é o fazer daquele que é gerente, que administra algo, portanto, que é responsável pela gestão, o termo gerencialismo agrega a este ato o pragmatismo, o tecnicismo, o controle e a premiação/punição a fim de obter os resultados estabelecidos. $O$ alcance de resultados está relacionado à ação prática, à resolução de problemas, à proatividade, ao individualismo e à competição.

Para isso, a ideia de profissionalização (formação, capacitação e qualificação) se torna imprescindível para eficiência no processo. $O$ estímulo para os "gerentes" é a premiação ou punição pelos resultados alcançados, fomentando a competição. Para possibilitar o conhecimento e parametrização dos resultados é fundamental medir a produção. Portanto, o fomento ao uso de instrumentos tecnológicos e desenvolvimento de ferramentas gerenciais também é preponderante para o alcance e contabilização de resultados. Além disso, se de um lado está o "gerente", do outro está o "cliente" a quem será prestado o serviço (Cf.: BRESSER-PEREIRA, 1997; 2001; 2010; e ABRUCIO, 1997).

Ao situar os atores nesse processo, a partir de uma lógica consumista, o prestador de serviço e o cliente mediados por um bem de consumo, que seria 0 serviço público, o gerencialismo caracteriza as instituições públicas como empresas regidas pela lógica mercantil. Assim, ideias de enxugamento de custos, qualidade do produto ou serviço, publicidade e produção tornam-se presentes nas atividades desenvolvidas pelas instituições públicas da mesma forma como estariam presentes nas empresas privadas. A adoção dessa ideologia para o serviço público está presente em diversos elementos da reforma do Estado, sobretudo, na reforma gerencial, impulsionando a mudança de concepção acerca

TrabalhoNecessário- www.uff.br/revistatrabalhonecessario: ano 16, №29/2018 
de conceitos tratados nos setores públicos que antes eram compreendidos por outra lógica social.

De acordo com Souza (2016b, p. 01):

Os termos "Gerencialismo" ou "Nova Gestão Pública"se referem às reformas governamentais de diversos países para superar a velha burocracia estatal por meio da propagação de nova cultura organizacional no serviço público, a qual identifica seus usuários como clientes de mesma natureza que aqueles de empresas privadas. O principal argumento do "gerencialismo" é a necessidade de superação do modelo burocrático de administração pública com foco nos procedimentos, cuja missão básica de servir a sociedade estaria comprometida, para instituir um novo modelo de administração pública com foco em resultados. Nesse sentido, esta nova perspectiva de administração pública se propõe a ir além do serviço burocratizado, pautado na mera execução de tarefas, segundo normas e procedimentos rígidos. Seu propósito é estabelecer um conjunto de procedimentos mais flexíveis e menos normatizados, orientados por dados mais precisos sobre os resultados alcançados por determinado órgão público ou empresa por ele contratada, de modo a garantir a prestação de contas dos governantes sobre o seu próprio desempenho - accountability oferecendo aos usuários (ou clientes) maior visibilidade dos resultados concretos do serviço público prestado, a pretexto de maior controle social. (SOUZA,2016b, p. 01).

A difusão do gerencialismo como paradigma para administração pública fomentada na reforma do Estado alcançou também a segurança pública, desde seu conceito. Reiner (2004) menciona que, a partir da década de 1970, as mudanças políticas e sociais incorreram em implicações profundas na segurança pública nos Estados Unidos e na Inglaterra e, a partir da década de 1990, o conceito gerencialista predominava para segurança pública.

O policiamento orientado para gestão de conflitos e o policiamento comunitário surgiram com base nesse conceito. A junção dos modelos foi encampada pela ONU (2009) no desenvolvimento do conceito de Segurança Cidadã., a segurança pública é um mecanismo de controle social a serviço da classe dominante que atua na aparelhagem estatal a fim de manter o status quo. $\mathrm{Na}$ medida em que avança o estágio de desenvolvimento do capital, a necessidade de sofisticar suas estratégias de mediação do conflito de classes também se vê expressa nessa nova concepção de segurança pública, onde o equilíbrio entre coerção e consenso passa a substituir a ideia de manutenção da

TrabalhoNecessário- www.uff.br/revistatrabalhonecessario: ano 16, №29/2018 
ordem pública por meio do uso da força bélica ${ }^{4}$. A essência não muda, mas muda a estratégia de atuação para o alcance do mesmo objetivo: a manutenção do status quo.

No Brasil, o termo segurança pública foi adotado na Constituição Federal de 1988 (BRASIL, 1988). Antes disto, o termo utilizado era segurança nacional. O deslocamento do nacional para o público aponta para demandas sociais da sociedade civil no lugar de demandas exclusivas da sociedade política a serem supostamente atendidas pelas polícias, assim, a atuação dos órgãos de segurança pública passa a ter como suposto foco a garantia do exercício dos direitos individuais e coletivos estabelecidos legalmente, a proteção das pessoas e do patrimônio público e privado e a prevenção e o controle de ações criminosas.

Passa-se a evocar a ideia de prestação de serviço de segurança, de modo que o cliente é a própria sociedade civil. $O$ deslocamento do público-alvo da condição de inimigo a ser combatido para a condição de cliente, o qual deve receber segurança, altera a concepção conservadora tradicional que pautava a atuação das instituições de segurança pública até então. Logo, a preservação da vida e da incolumidade e a proteção da pessoa concebem o uso de estratégias de mediação entre coerção e consenso e não apenas coerção, embora o Estado continue detendo o monopólio da violência.

Por outro lado, a concepção de que os profissionais de determinada atividade são gerentes também foi adotada no que chamamos de conceito conservador progressista de segurança pública ${ }^{5}$. Nesta perspectiva, os policiais se tornariam responsáveis por gerir conflitos; seriam, portanto, gerentes na prestação do serviço de segurança pública; da complexidade presente nessa tarefa emerge a demanda de profissionalização (formação inicial e continuada) fomentada pelo gerencialismo.

\footnotetext{
4 "Enquanto a interiorização pode fazer o seu bom trabalho, para assegurar os parâmetros reprodutivos abrangentes do sistema capitalista, a brutalidade e a violência podem ser postas de parte (embora de modo algum permanentemente abandonadas) como modalidades dispendiosas de imposição de valor, como de facto aconteceu no decurso dos desenvolvimentos capitalistas modernos. Apenas em períodos de crise aguda se dá de novo projecção ao arsenal da brutalidade e da violência com o objectivo de impor valores" (MÉSZÁROS, 2005, p. 14).

5 Denominamos como conservador progressista tomando por empréstimo a concepção gramsciana de frações de classe (GRAMSCI, 1980). O conceito conservador progressista de segurança pública agrega ideias gerenciais para segurança pública e adota modelos de policiamento orientado para a gestão de conflitos, como a polícia comunitária. A nomenclatura da ONU para esse tipo de policiamento é Segurança Cidadã (ONU, 2009).
}

TrabalhoNecessário- www.uff.br/revistatrabalhonecessario: ano 16, №29/2018 
Nesse sentido, a formação policial torna-se elemento fundamental para atuação desse profissional. As exigências para esse profissional têm aumentado a partir de então, tanto para o ingresso nas instituições policiais, quanto para a continuidade de atuação daqueles que ingressaram sem muitas exigências, o uso de equipamentos e tecnologias sofisticados nas instituições de segurança pública, bem quanto a própria sofisticação das ações criminosas, são elementos que demandam profissionalização e desenvolvimento profissional.

Além disso, há relação com o próprio desenvolvimento das atividades das instituições de segurança pública, que passaram a ser geridas segundo as diretrizes e estratégias típicas do modelo gerencialista, com vistas ao alcance de resultados.

Enfim, a partir da reforma gerencial, o profissional de segurança pública é conduzido ao status de gerente, sua atuação ao status de produção, a sociedade ao status de cliente e a segurança pública ao status de produto, contudo, o policiamento mediado entre coerção e consenso é o mínimo a ser feito no que diz respeito ao fomento dos direitos humanos. Por outro lado, é importante ressaltar que esse é o limite a ser alcançado pelas instituições de segurança pública no Estado capitalista. Limite esse que ainda está longe de ser realidade no Brasil.

\section{Da política de segurança pública à política pedagógica do CFSd}

As pressões internacionais que resultaram no desenvolvimento de políticas para segurança, em âmbito nacional e, em âmbito estadual, no Rio de Janeiro, levaram à implementação de ações para formação policial no sentido de efetivar a reorientação da política de segurança pública. Citamos como exemplo o Projeto de Cooperação Técnica Internacional BRA/04/029 - Segurança Cidadã, iniciado em 2004, que além da proposta de implementação do Sistema Único de Segurança Pública (SUSP) ${ }^{6}$, teve como objetivo o apoio às ações de formação e de valorização profissional para segurança pública. Assim, surgiu a demanda pela criação de um currículo que uniformizasse a formação dos profissionais de

\footnotetext{
${ }^{6}$ Os Projetos de Lei no 3734/2012 e PL 3735/2012 que tratam da implementação do SUSP ainda estão em tramitação.
}

TrabalhoNecessário- www.uff.br/revistatrabalhonecessario: ano 16, №29/2018 
segurança em território nacional. O desenvolvimento de tal currículo proposto nesse acordo foi finalmente implementado em 2009.

A Matriz Curricular Nacional (MCN) para ações formativas dos profissionais da área de segurança pública (BRASIL, 2009) desenvolvida no ano de 2009 e revisada no ano de 2014 (BRASIL, 2014) visa a formação, capacitação e qualificação profissional na área de segurança pública em âmbito nacional. Já no estado do Rio de Janeiro, em 2011, foi regulamentado o exercício de encargos referentes às atividades de ensino no âmbito da segurança pública (RIO DE JANEIRO, 2011), a partir do qual foi criado o Programa Banco de Talentos; em 2012, foi criada a Subsecretaria de Educação, Valorização e Prevenção (SSEVP) (RIO DE JANEIRO, 2012b) e desenvolvido o currículo para os cursos de formação de praças da PMERJ (RIO DE JANEIRO, 2012a). Em 2015, a institucionalização, planejamento e controle da política de pacificação no estado do Rio de Janeiro (RIO DE JANEIRO, 2015a) ratifica a relação entre tal política pública e o conceito de segurança cidadã da ONU.

A implementação dessas medidas tem como objetivo a difusão da política pública, a conformação social a essa política e a reprodução do conceito de segurança pública sob viés gerencialista, a fim de superar o tradicionalismo e assim estabelecer-se hegemonicamente em um contexto mais complexo das relações entre Estado e sociedade civil.

Embora não tenhamos encontrado um documento denominado Projeto Político Pedagógico (PPP) para as atividades de ensino na PMERJ, encontramos a orientação ou proposta político pedagógica em alguns documentos normativos dos processos educativos na PMERJ. A Diretriz Geral de Ensino e Instrução DGEI-D9 (PMERJ, 2004), como a MCN (BRASIL, 2009; 2014) e também o Currículo de Soldados, Cabos e Sargentos (RIO DE JANEIRO, 2012a) fomentam aspectos políticos e pedagógicos para a formação profissional.

Esse último documento foi desenvolvido em ação conjunta com a SSEVP, órgão criado para orientar a formação policial dos efetivos que atuam principalmente na atividade fim, sobretudo praças e agentes da polícia civil, ou seja, agentes que atuam na base das instituições de segurança pública, além de instituir o Banco de Talentos que tem relação direta com a implementação da 
política de segurança pública ${ }^{7}$. Nesse sentido, observamos que a DGEI-D9 (PMERJ, 2004), a MCN (BRASIL, 2009; 2014) e o Currículo de Soldados, Cabos e Sargentos (RIO DE JANEIRO, 2012a) são elementos fundamentais para compreensão da política pedagógica desenvolvida para formação policial militar no Rio de Janeiro.

A DGEI-D9 (PMERJ, 2004), desenvolvida no mesmo ano do Acordo de Cooperação Técnica Internacional mencionado anteriormente, propõe a "adoção de um novo modelo de gestão calcado, dentre outros atributos, na capacidade gerencial altamente qualificada, com vistas à adoção de novas rotinas de pronta resposta em face do anseio da sociedade" (PMERJ, 2004, p. 2). Assim, logo no início do documento fica clara a proposta política para formação dos profissionais de segurança da PMERJ, voltada para a formação de um policial militar capacitado para gestão, prevenção, mediação e resolução de conflitos.

Além disto, percebe-se clara proposição de substituição do caráter militarista, imbuído no ideal da força, pela demanda de prestação de serviço à sociedade, conforme descrito a seguir:

[...] significa a superação do paradigma histórico de natureza militarista, fortemente alicerçado na crença de que a ideia de serviço deva necessariamente se subordinar à ideia de força. A noção exata que justamente traduz o sentido de ser da organização policial como instituição destinada a proteger e a servir a sociedade e de garantir a ordem democrática é diametralmente oposta ao preceito mencionado, ou seja, na busca legítima dos requisitos legais e técnicos inerentes ao exercício da autoridade moral e policial a ideia de força deve, necessariamente, estar subordinada à ideia de serviço (PMERJ, 2004, p. 3).

O objetivo principal dos processos de ensino-aprendizagem na PMERJ, de acordo com a DGEI-D9 (PMERJ, 2004, p. 3), é o desenvolvimento profissional e humano dos policiais militares, com vistas à valorização e ao reconhecimento profissional. O Art. 3ํ da DGEI-D9 (PMERJ, 2004, p. 6) esclarece que a atividade de ensino e instrução na PMERJ

\footnotetext{
${ }^{7} \mathrm{~A}$ atividade docente é elemento central na formação do policial, com poder de desenvolver ou de frustrar a política pedagógica adotada. Nesse sentido, a contratação de professores por um órgão externo às polícias, os quais são avaliados a partir do currículo mínimo delineado pela SSEVP, torna-se uma medida política vista como estratégica na garantia de efetivação da segurança cidadã.
}

TrabalhoNecessário- www.uff.br/revistatrabalhonecessario: ano 16, №29/2018 
[...] tem por finalidade o pleno desenvolvimento das qualidades e das aptidões intelectuais, psicológicas, físicas, éticas e morais, inerentes às atribuições funcionais do profissional de segurança pública, seu preparo para fazer cumprir a Lei e garantir o exercício da cidadania e sua qualificação continuada para o trabalho (PMERJ, 2004, p. 6).

A MCN (BRASIL, 2009; 2014) serve para orientar a construção de currículos para ações formativas por parte das instituições de segurança pública, a partir de eixos articuladores e áreas temáticas, buscando o desenvolvimento de "competências específicas necessárias para responder aos desafios sem precedentes das ações concretas da área de segurança pública” (BRASIL, 2014, p. 17). Desse modo, propõe "ser um referencial teórico-metodológico que orienta as Ações Formativas dos Profissionais da Área de Segurança Pública [...] independente da instituição, nível ou modalidade de ensino" (BRASIL, 2014, p. 17). O objetivo geral da MCN é:

[...] favorecer a compreensão do exercício da atividade de segurança pública como prática da cidadania, da participação profissional, social e política num Estado Democrático de Direito, estimulando a adoção de atitudes de justiça, cooperação, respeito à Lei, promoção humana e repúdio a qualquer forma de intolerância (BRASIL, 2014, p. 40).

De acordo com o delineamento dado à MCN (BRASIL, 2014), a formação para segurança pública deve estar imbricada à ideia de autonomia intelectual, conceituada como capacidade de adaptação, de ação e de gestão frente a diversas situações a que o profissional de segurança pública é submetido no exercício da profissão. Essa autonomia seria produto de um processo de aprendizagem para crítica da cultura consolidada nas instituições (BRASIL, 2014). Assim, a MCN visa o desenvolvimento das "capacidades de análise, síntese, crítica e criação" (BRASIL, 2014, p. 52), de modo que o profissional de segurança pública alcance competências cognitivas, operativas e atitudinais, a fim de que seja capaz de pensar crítica e criativamente sobre a própria atuação profissional e sobre sua interação e convivência com o outro, nos ambientes onde atua (BRASIL, 2014).

No ano de 2012, a partir de ação conjunta com a PMERJ, a SSEVP desenvolveu o Currículo para os cursos de formação de soldados, cabos e

TrabalhoNecessário- www.uff.br/revistatrabalhonecessario: ano 16, №29/2018 
sargentos (RIO DE JANEIRO, 2012a). Logo no início, está claro no documento que a motivação para sua confecção está relacionada à implementação da política de segurança pública:

Essa proposta é uma reflexão que tem como ponto de partida a atual política de segurança pública adotada pela Secretaria de Estado da Segurança do Rio de Janeiro, na qual os processos de aprendizagem passam a ter contornos de uma ponte entre as atividades policiais e as dinâmicas e demandas da sociedade (RIO DE JANEIRO, 2012a, p. 4).

Nesse contexto, o documento toma a formação de policiais militares como elemento fundamental, porquanto são os reais executores da política de segurança pública desenvolvida pelo governo. Por isso, a proposta da SSEVP é para formação inicial e continuada realizada pelo Centro de Formação e Aperfeiçoamento de Praças (CFAP):

Este cenário exige, por parte do Centro de Formação e Aperfeiçoamento de Praças, CFAP 31 de Voluntários - instituição responsável pela formação técnico-profissionalizante e continuada da Polícia Militar do Estado do Rio de Janeiro (PMERJ) que oferece a formação para Soldados, Cabos e Sargentos, bem como cursos de aperfeiçoamento - a implementação de novas ações organizativas e pedagógicas referentes a otimização de tempos e espaços de formação. Numa dimensão politicamente mais ampla, essas demandas estão alinhadas às diretrizes da SESEG, que elegeu a educação como princípio norteador das mudanças a serem realizadas (RIO DE JANEIRO, 2012a, p. 6).

O documento aponta como referencial as diretrizes estabelecidas pela ONU para o desenvolvimento da Segurança Cidadã (RIO DE JANEIRO, 2012a, p. 19), mencionando também a importância das parcerias com setores privados para a diminuição da violência. Tal currículo busca alinhar a formação policial militar à proposta político pedagógica para formação dos profissionais da segurança pública em âmbito nacional (BRASIL, 2014) e à política de segurança pública do estado do Rio de Janeiro. Assim, o objetivo geral para formação de praças, tanto para os cursos de formação inicial, quanto para os cursos de formação continuada é "criar condições para que os policiais em formação possam: ampliar conhecimentos; desenvolver habilidades técnicas e cognitivas; e fortalecer 
atitudes pessoais e corporativas necessárias à sua atuação como operadores de segurança pública" (RIO DE JANEIRO, 2012a, p. 11).

Desenvolvendo um perfil profissional de "policiais militares reflexivos, conscientes e participativos, capazes de interagir e intervir na realidade" (RIO DE JANEIRO, 2012a, p. 9). Para isso, as ações educacionais "devem estar voltadas para o desenvolvimento das competências profissionais necessárias à atuação do operador de segurança pública no contexto social atual, considerando a indissociabilidade com os Direitos Humanos" (RIO DE JANEIRO, 2012a, p. 7).

O currículo está dividido em quatro módulos: Módulo Comum - 184h; Módulo Profissional - 430h; Módulo Jurídico - 128h; e, Módulo Complementar 440h, com carga horária total de 1182 h, distribuídas em 30 disciplinas a serem concluídas em aproximadamente 27 semanas no CFSd. A maior carga horária do currículo é dispensada ao Módulo Complementar (37,2\% da carga horária do curso). Neste módulo, a metade da carga horária é destinada à realização de avaliação (100 horas) e "coordenação pedagógica" (120 horas).

A análise preliminar do currículo aponta contradições com a política pedagógica descrita no próprio documento (RIO DE JANEIRO, 2012a) e com os demais documentos que toma como referenciais - DGEI-D9 (PMERJ, 2004) e MCN (BRASIL, 2009; 2014). A ênfase no Módulo Complementar o põe como foco principal para formação policial militar. Entendemos que a flexibilidade que tal condição infunde à formação possibilita que o currículo siga por direções contrárias à política pedagógica sem burlar o planejamento estabelecido. Não estão delimitadas, por exemplo, as abordagens contidas nas "atividades extracurriculares - palestras" (80h); tampouco, informa quais atividades são desenvolvidas na "coordenação pedagógica" (120h).

Observamos ainda que a disciplina "Educação Física" recebe a maior carga horária dentre as demais disciplinas do curso $(10,1 \%)$, seguida de "Tiro Policial" (5,9\%). Considerando que a disciplina "Método de Defesa Policial Militar" (2,5\%) tem conteúdo relacionado à prática de atividades físicas, as disciplinas voltadas à atividade física abrangem $12,6 \%$ da carga horária total. Além disso, agregando a disciplina "Armamento" (4,2\%) à disciplina "Tiro Policial" (5,9\%), temos 10,1\% da carga horária total, dispensados ao uso de armas de fogo. Portanto, as quatro

${ }^{8} \mathrm{O}$ currículo não conceitua o termo, tampouco estabelece a que se destina.

TrabalhoNecessário- www.uff.br/revistatrabalhonecessario: ano 16, №29/2018 
disciplinas da MCN (BRASIL, 2009) relacionadas ao "Uso da Força" (5\%), na matriz curricular do CFSd (RIO DE JANEIRO, 2012a) compreendem $22,7 \%$ da carga horária do curso. Além disso, o "Módulo Jurídico" compreende 10,8\% da carga horária total, muito embora, duas disciplinas de teor jurídico estejam dispostas no módulo profissional, a saber, "Legislação Aplicada a PMERJ I" e "Legislação Aplicada a PMERJ II", que juntas somam 3,2\% da carga horária total se agregadas ao Módulo Jurídico, compreenderiam 14\% do curso. Somando a carga horária dispensada à atividade física $(22,7 \%)$, ao conhecimento jurídico (14\%) e ao módulo complementar $(37,2 \%)$ concluímos que $73,9 \%$ da carga horária total do curso é dispensada, a tais conhecimentos.

A ênfase da carga horária para atividades físicas reforça a ideia de que o bom profissional de segurança pública tem o perfil próprio para o combate e está inserto em um determinado padrão de força e resistência próprio de "guerreiros". O ideal de policial super-herói é agravado ainda pela ideia deturpada de direitos humanos presente nas instituições policiais, baseada no discurso de que é "coisa de defesa de bandido" (GUIMARÃES, 2000, p. 48) e contrária aos interesses dos policiais. Tal compreensão retroalimenta a ideia de desumanização do policial, pois se ele é "homem-máquina", herói, não é humano, logo, Direitos Humanos não são seus próprios direitos.

Enfim, tanto a DGEI-D9 (PMERJ, 2004), quanto o Currículo para Soldados, Cabos e Sargentos (RIO DE JANEIRO, 2012a) estão alinhados à proposta político-pedagógica presente na MCN (BRASIL, 2009; 2014a), no que diz respeito aos objetivos da formação policial militar e o perfil profissional que se pretende alcançar. O policial deve ser capacitado para gestão de conflitos, seja pela prevenção, seja pela mediação, seja pela resolução. Além disso, essa proposta político-pedagógica está alinhada ao novo conceito de segurança pública.

Portanto, delineia um perfil policial militar voltado à prestação de serviço, que cumpre a lei e que seja um promotor dos direitos humanos. Contudo, a materialização de tal proposta não chegou a promover alterações substanciais no currículo dos cursos de formação policial militar. O máximo alcançado até o momento foi a inserção de uma carga horária para a disciplina Direitos Humanos, mesmo assim, abaixo do proposto pela Secretaria Nacional de Segurança Pública (SENASP).

TrabalhoNecessário- www.uff.br/revistatrabalhonecessario: ano 16, №29/2018 
Além da criação de órgãos, programas, propostas legais e currículos para formação dos policiais militares sob a concepção de segurança pública conservadora progressista, é importante esclarecer as influências da política pedagógica no discurso dos gestores da formação policial militar e do próprio policial militar formado a partir dessa concepção. Para tanto, trazemos alguns dados coletados durante pesquisa de campo (VEIGA, 2016).

A partir de entrevistas com os gestores da formação de soldados - 0 comandante do Centro de Formação e Aperfeiçoamento de Praças (CFAP); o diretor da Diretoria Geral de Ensino e Instrução (DGEI) e o superintendente de educação da SSEVP, da Secretaria de Estado de Segurança (SESEG) concluímos que estão alinhados com a concepção de segurança pública adotada pelo estado do Rio de Janeiro. Houve unanimidade acerca da demanda de adoção do conceito de segurança pública norteado pela prestação de serviço e gestão de conflitos pela mediação entre coerção e consenso.

Nós já saímos da era dessa questão de meter o pé na porta, isso não existe mais... de jogar bomba... dizem que é tiro, pancada e bomba, isso daí já... ultrapassamos essa esfera. Temos que evoluir e agora caminha para esse aspecto social de preparação, de diálogo, de conversa, de um verdadeiro resolvedor de problemas (Diretor da DGEI).

[...] eu imagino que a Secretaria pense que o soldado formado, ele é, antes de tudo, um prestador de serviço e um administrador de conflitos; acho que se fosse pra resumir, eu resumiria dessa forma, né (Superintendente de educação da SSEVP).

[...] o produto que se forma aqui é o grande projeto da Secretaria de Segurança Pública. [...] prá gente, enfim, tentar formar um policial aqui com essa inclinação, com uma inclinação mais é humana, de dignidade, de proximidade, então, eu tento que primar por isso. [...] aliás, se em torno de $65 \%$ das nossas ocorrências são assistenciais, por que que eu quero que saia daqui um policial um exímio atirador? Ele tem que saber tratar gente, ele tem que saber dirimir conflito (Comandante do CFAP).

Além disso, foram mencionadas, durante as entrevistas, as demandas de modernização das atividades desenvolvidas pela PMERJ e de profissionalização dos policiais militares propagadas pela ideologia gerencial. Entretanto, foram evidenciados alguns fatores que emperram o desenvolvimento desse modelo de gestão, de acordo com os entrevistados: a) ausência de investimentos financeiros adequados à demanda da formação policial de modo amplo; b) demanda de 
medidas de qualificação e capacitação de todo quadro efetivo; c) política de contratação e seleção e valorização profissional. Tais fatores têm implicação direta no projeto estatal para difusão de um novo conceito de segurança pública.

Aplicamos questionário a um grupo de 983 policiais militares do estado do Rio de Janeiro que realizaram o CFSd em algum momento de suas carreiras. Nesse questionário com 58 perguntas, coletamos dados a respeito do CFSd e características do público pesquisado. É importante esclarecer que o perfil dos sujeitos investigados é homogêneo: formado por policiais militares que ingressaram pelo concurso de soldados no período de 1980 a 2015 e estavam na ativa no ano de 2016; e diversificado de acordo com as características profissionais existentes na instituição: quanto ao gênero, idade, grau hierárquico, área de atuação, escolarização, tempo de profissão, etc. Considerando os limites desse artigo, analisamos um único aspecto coletado durante a aplicação dos questionários: a prática pedagógica adotada.

Estipulamos questões referentes à carga horária praticada; à carga horária praticada para atividades físicas e o tipo de atividades praticadas para condicionamento físico; à prática de punições; ao uso de canções e jargões militares e aspectos culturais coletados em duas questões discursivas.

No que diz respeito à carga horária praticada durante o CFSd, $60 \%$ dos sujeitos investigados informaram que o curso não era realizado em regime de internato ou semi-internato, contudo, mais de $60 \%$ informaram que o horário de início das atividades diárias era até seis horas da manhã. Não foram poucas as queixas de que o curso exige demais dos alunos, expondo-os a cargas horárias diárias superiores a 12 horas.

Considerando que a carga horária estabelecida no currículo do CFSd é de 1.182 horas, distribuídas em 27 semanas, isso equivale a 43,77 horas semanais e 8,75 horas diárias (de segunda à sexta). Se o aluno cumpre uma carga horária diária de 12 horas, o curso é aumentado em mais de 400 horas, o que representa um aumento de quase $30 \%$ da carga horária estabelecida. Tendo em vista que todas as disciplinas do currículo têm carga horária estipulada, tais horas a mais poderiam ser utilizadas para reforçar algum conhecimento específico presente ou não no currículo ou seriam utilizadas para práticas de atividades físicas e treinamento militar. 
Por outro lado, segundo coletado durante a pesquisa, as atividades físicas ainda contam com práticas degradantes, como a exposição ao sol por mais de 2 horas e realização de exercícios em solo quente. A evidência dada às atividades físicas e ao treinamento militar impactou o grupo pesquisado, de modo que $50 \%$ dos sujeitos respondeu que esse foi o conhecimento mais importante durante 0 CFSd, seguido de uso da força. Segundo esse entendimento, é provável que a carga horária extra seja utilizada para realização de alguma atividade física, que já tem carga horária expressiva no currículo, conforme mencionado anteriormente.

Esse fato demonstrado pelos sujeitos pesquisados quando solicitado que dissessem uma frase que marcou o CFSd e as respostas foram: "cai", "paga", "correndo", "de pé 1, 2", "para posição de flexão", "flandu" e até "tortura" foram mencionadas, além de que a palavra "suga" foi a mais registrada nesse espaço do questionário. Em outra questão aberta, além das críticas à excessiva carga horária e ao esgotamento físico durante o CFSd, ainda houve referências ao emprego de alunos para limpeza das instalações no horário do curso:

Infelizmente, o que mais aprendi, nos meus 6 meses de curso foi pegar em uma vassoura.... (ANÔNIMO, em 01/06/2016, às 18:13:11h).

Tempo de treinamento deveria ser melhor empregado, ou seja, menos suga + profissionalismo (ANÔNIMO, em 2016/05/19, às 9:41:10h).

Quando questionamos quais as disciplinas menos importantes durante o CFSd, $50 \%$ dos sujeitos investigados responderam direitos humanos e, em segundo lugar, treinamento militar, a evidência da polarização entre direitos humanos e treinamento militar é notada pela repulsa de uma e exaltação da outra, com a mesma proporção pelo mesmo grupo.

A tensão entre duas concepções de segurança pública é evidente aqui: a concepção conservadora tradicional valoriza a militarização, enquanto a concepção conservadora progressista faz emergir o debate acerca de direitos humanos. Quando os sujeitos investigados apontam esses dois conhecimentos como menos importantes, é evidenciada a tensão e disputa por hegemonia entre as duas concepções de segurança pública apresentadas. Esse fato demonstra, sobretudo, a tensão entre a prática pedagógica tradicional adotada no CFSd e a

TrabalhoNecessário- www.uff.br/revistatrabalhonecessario: ano 16, №29/2018 
política pedagógica progressista presente nas propostas de mudança na segurança pública explicitadas em outdoor na entrada do CFAP dizendo que: "a pacificação começa aqui". Contradição também observada nos trechos:

O curso necessita que seja realizado uma formação que privilegia a formação profissional e menos militar (ANÔNIMO, em 08/06/2016, às 18:02:04h).

Deve-se pensar em formar verdadeiros policiais, e não um grande número de guerrilheiros urbanos (ANÔNIMO, em 01/06/2016, às 20:44:52h).

A formação policial deve ser mudada, não somos máquinas de guerra que defendem o Estado (ANÔNIMO, em 01/06/2016, às 22:29:20h).

Penso que nos preparam para enfrentarmos bandidos e a sermos sanguinárias. Porém, na verdade, não é isso que acontece aqui fora. No curso te ensinam a bater; aqui fora, se vc bate vc vai preso (ANÔNIMO, em 02/06/2016, às 00:32:27h).

Existe uma cultura que impõe a dualidade no pensamento do aluno, pois, por vezes, ele é incentivado a agir como um verdadeiro servidor público garantidor da cidadania; mas, paradoxalmente, é preparado e incentivado a ser um infante implacável na luta contra os "'"inimigos"'", normalmente os traficantes de entorpecentes e ladrões em geral (ANÔNIMO, em 02/06/2016, às 16:49:59h).

Além disso, mais de $50 \%$ dos sujeitos investigados informaram que

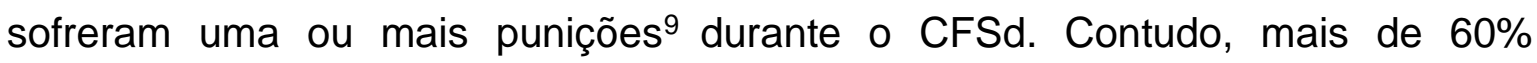
informaram que os alunos realizavam exercícios físicos e mais de $30 \%$ informaram que os alunos eram submetidos à extensão do horário de saída como formas de punição aplicadas durante o CFSd. O uso do Regulamento Disciplinar como instrumento pedagógico para moldar o policial militar é incrementado pelas diversas possibilidades de punição dada a falta de regulação de direitos trabalhistas da categoria. O uso de exercícios físicos, escalas extra, aumento da carga horária diária pela alteração de horários de entrada e saída são exemplos dessas estratégias coercitivas de uma prática pedagógica tradicional.

[...] infelizmente o maior aprendizado no curso era o medo dos oficiais e dos policiais mais antigos, pois, por qualquer motivo

\footnotetext{
${ }^{9}$ Consideramos nesta questão apenas punições elencadas no Regulamento Disciplinar da PMERJ (advertência verbal e escrita, detenção e prisão).
} 
pagava-se flexão, éramos esculachados verbalmente na frente de todos e ficávamos de LS, ou seja, detidos aos finais de semana a troco de nada (ANÔNIMO, em 01/06/2016, às 19:22:01h).

[...] bem, infelizmente, o curso de formação de praças contribui muito pouco para a formação de um profissional de segurança pública, infelizmente. Onde, ao invés de preparar o aluno para tal, ficam utilizando o militarismo de uma forma negativa. [...] utilizamse do militarismo para abusar do aluno em faxinas, serviços extras (muitos deles sem necessidade e sem propósito) e tratamento desrespeitoso à figura do aluno. sendo o aprendizado técnico ficado em último plano. Ou seja, formando profissionais despreparados, que vão adquirir qualificação, na vivência policial (ANÔNIMO, em 06/06/2016, às 16:45:43h).

Carga horária de $13 \mathrm{~h}$ por dia e quando era meio expediente, liberavam-nos às 14h. Desfile militar após as 18:30, horário regulamentar de expediente até às 17:40, no entanto, fomos liberados após às $20 \mathrm{~h}$ apenas com alimentação do almoço às $11 \mathrm{~h}$, após esses desfiles (ANÔNIMO, em 09/10/2016, às 12:26:48h).

Outro aspecto que demonstra a prática pedagógica adotada é o uso de canções e jargões militares. Cerca de $50 \%$ dos sujeitos investigados informaram que as letras das canções "incentivavam a sobrevivência" e a "guerra contra os inimigos". Além de outros $30 \%$ que informaram que as letras das canções traziam "temas sobre morte". Os percentuais apresentados demonstram o conceito de segurança pública conservador presente no uso dessas canções.

Os sujeitos investigados que ingressaram na década de 2010 relataram proporções menores acerca de temáticas sobre combate aos inimigos, violência e morte, o que representa alguma mudança nesse aspecto no período.

Por fim, também foi relatado o uso de xingamentos e expressões como "você foi voluntário", "não está satisfeito, pede pra ir embora”, "o cachorro é mais antigo que você", "você é um número", "recruta maldito", "imagem do cão", "bisonho", “lixo", “animal”, "monstro", “FEM maldita”, "louco". Tais práticas impactaram negativamente o momento do ingresso dos sujeitos investigados na PMERJ, a ponto de $70 \%$ dos sujeitos investigados terem informado que 0 momento de maior aprendizagem profissional se deu após o CFSd.

[...] o uso de violência nos cursos de especialização acredito não somar nada ao profissional, pois sempre ouvi falar que aprende apanhando ensina batendo, logo, nos cursos de especialização são a base a porrada, afogamento e tortura. Então, para que ser submetido a esse tipo de tortura se não podemos aplicar sobre 0 público alvo? (ANÔNIMO, em 6/2/2016, às 10:34:05h). 
Sofri grandes pressões psicológicas e físicas durante o curso, que só serviram para me influenciar negativamente. $\mathrm{E}$ me causar danos até hoje! Passei dificuldades financeiras devido a falta de pagamento dos primeiros meses de curso e recorri a empréstimos consignados, que sangram meu orçamento até hoje. $O$ ensino é péssimo e em poucos momentos, segundos, foi voltado prô meu serviço policial que desempenharia...e sim uma lavagem cerebral de como a polícia é boa \#sqn, e disseminação do medo dos seus superiores (ANÔNIMO, em 6/2/2016, às 10:21:51h)

A primeira palavra de chamamento no primeiro dia foi "Animal" (ANÔNIMO, em 01/06/2016, às 19:48:34h).

Foi possível obter junto aos sujeitos investigados que a carga horária praticada é significativamente superior à estabelecida, como também a carga horária praticada para atividades físicas. Além disso, o tipo de atividades praticadas para condicionamento físico inclui práticas degradantes. A prática de punições de modo expressivo e o uso de canções, jargões militares e expressões voltadas ao "enquadramento" do policial em um determinado ethos guerreiro são fatos que demonstram uma prática pedagógica voltada à coerção.

\section{Conclusões}

Concluímos que a política de segurança pública explicitada em documentos no estado do Rio de Janeiro não se materializou na política pedagógica do CFSd. A ausência de padrões normatizados institucionalmente para sistematizar o desenvolvimento da política pedagógica de acordo com a política de segurança contribui para adoção de práticas inadequadas destinadas à manutenção e reprodução dos padrões tradicionalistas. Por outro lado, a política pedagógica adotada serve para forjar um profissional submisso e minimamente reflexivo. O currículo é aplicado por meio de uma pedagogia da coerção, a partir de punições e excessiva prática de atividades físicas. Assim, a submissão produzida coercitivamente capacita o policial militar a cumprir sua função na condição de agente do aparelho repressivo do Estado em favor do capital, para garantia da manutenção e reprodução do status quo. Desse modo, a sofisticação das estratégias de mediação de conflitos e construção do consenso para obtenção de hegemonia, desenvolvidas a partir da perspectiva gerencial, não chegou a interferir na pedagogia tradicional utilizada para formação inicial do policial militar do Rio de Janeiro.

TrabalhoNecessário- www.uff.br/revistatrabalhonecessario: ano 16, №29/2018 
Nossa compreensão é de que ficou bastante explícita a contradição entre a política de segurança pública pautada na perspectiva da mediação de conflitos proposta nos documentos analisados e aquela pautada na perspectiva da ação coercitiva verificada na prática pedagógica dos CFSd. Esta contradição expressa a tensão vivida no interior da própria classe dominante. Trata-se de uma contradição intraclasse na concepção e na política de segurança pública que perpassa toda as ações gerenciais dos órgãos de segurança, a relação entre as forças policiais e a sociedade e, obviamente, na formação inicial dos policiais militares. O fato é que, em pleno processo de recomposição burguesa diante da crise orgânica do capital, a fração mais moderna do bloco no poder enfrenta o desafio de suplantar as forças tradicionais ainda vivas em seu interior para fazer valer seus esforços de renovação dos mecanismos de mediação do conflito de classes, com vistas na manutenção de sua hegemonia em condições renovadas.

Tal contradição se expressa na própria existência de uma polícia militar em nossa sociedade em um regime democrático instalado após a ditadura civil-militar. Outro exemplo é nossa legislação, que expressa um discurso em que predomina a perspectiva da mediação de conflitos para obtenção de consenso, pautada em ideais democráticos, mas sua aplicação, em especial quando se trata das camadas mais pobres, se dá predominantemente pelo uso de ações coercitivas e autocráticas.

Em outro aspecto, esta contradição também pode ser compreendida como uma "cortina de fumaça" para ofuscar a natureza autoritária e coercitiva de um sistema social de produção e reprodução da vida material fundado na exploração de uma classe por outra, mas que necessita do consentimento ativo da sociedade civil para se estruturar e se reproduzir. Em um sistema como esse, em última análise, a política de segurança pública funciona para a manutenção do status quo, ainda que determinada pela contradição entre consenso e coerção, o que se percebe claramente na formação inicial do policial militar investigada.

\section{Referências}

ABRUCIO, Fernando Luiz. O impacto do modelo gerencial na administração pública: um breve estudo sobre a experiência internacional recente. Cadernos ENAP, Brasília, № 10, 1997. 
BRASIL. Constituição (1988). Constituição da República Federativa do Brasil. Brasília, DF, $1988 . \quad$ Disponível em: $<$ http://www.planalto.gov.br/ccivil_03/Constituicao/Constituicao.htm>. Acesso em: 05/05/2015.

Brasília, MF, $1995 . \quad$ Disponível Estado. $<$ http://www.bresserpereira.org.br/documents/mare/planodiretor/planodiretor.pdf>. Acesso em: 02 mai. 2015.

SENASP (2009). Ministério da Justiça - Secretaria Nacional de Segurança Pública. Matriz Curricular Nacional Para Ações Formativas dos Profissionais da Área de Segurança Pública. Brasília, DF, 2009.

- SENASP (2014). Ministério da Justiça - Secretaria Nacional de Segurança Pública. Matriz Curricular Nacional Para Ações Formativas dos Profissionais da Área de Segurança Pública. Brasília, DF, 2014.

BRESSER-PEREIRA, Luiz Carlos. A Reforma do Estado nos anos 90: lógica e mecanismos de controle. Cadernos MARE, Caderno 01, Brasília, 1997.

. Democracia, Estado Social e Reforma do Estado. Artigo. São Paulo, Revista de Administração de Empresas, Vol. 50, no 1, Jan-Mar, 2010. Disponível em: $<$ http://www.scielo.br/scielo.php?pid=S003475902010000100009\&script=sci_arttext>. Acesso em: 30 mai. 2015.

. A administração pública gerencial: estratégia e estrutura para um novo Estado. Cadernos ENAP, Brasília, 2001. Disponível em < http://www.enap.gov.br/documents/586010/601535/9texto.pdf/6f1673a4-be8f4a8b-9002-df02f779993e>. Acesso em: 02/05/2015.

CHOMSKY, Noam. O lucro ou as pessoas. São Paulo: Bertrand Brasil, 1999.

GRAMSCI, Antonio. Escritos políticos. Vol. I. Lisboa: Seara Nova, 1976.

. Notas sobre Maquiavelo, sobre la política y sobre el estado moderno.

Buenos Aires: Nueva Vision, 1980.

. Maquiavel, a política e o Estado moderno. $7^{\text {a }}$ Ed., Rio de Janeiro, 1989.

GUIMARÃES, Luiz Antônio Brenner. Valores institucionais, a prática policial militar e a cidadania. Revista Unidade, Porto Alegre, no 41, p.45-85, Jan a Mar/2000.

HARVEY, David. Breve historia del neoliberalismo. Madri: Ed. Akal, 2007.

HOBSBAWM, Eric. A Era do Capital-1848-1875. São Paulo: Paz e Terra, 1977.

MARX, Karl; ENGELS, Friedrich. Manifesto Comunista. Instituto José Luis e Rosa Sundermann, 2003. Disponível em: 
<http://www.pstu.org.br/sites/default/files/biblioteca/marx_engels_manifesto.pdf>, acesso em 07/11/2015.

MÉSZÁROS. Istvan. Para além do capital. São Paulo: Boitempo, 2002. . Educação para além do capital. São Paulo, Boitempo, 2005.

PMERJ. DGEI (2004). Diretriz Geral de Ensino e Instrução PMERJ (DGEI - D9), de 23 de novembro de 2004. Público no Aditamento ao Boletim PMERJ oㅡ 076, de 23 de novembro de 2004. Rio de Janeiro, 2004.

Projeto Segurança Cidadã. In: ONU, PNUD, 2009. Disponível em: $<$ http://www.pnud.org.br/publicacoes/segurancacidada_trabalhoPNUD.pdf>.

Acesso em: 31/08/2016.

REINER, Robert. A política da polícia. Tradução: Jacy Cardia Ghirotti e Maria Cristina Pereira da Cunha Marques. Série: Polícia e Sociedade, Vol. 11, Núcleo de Estudos da Violência da Universidade de São Paulo (NEV/USP). São Paulo, Edusp, 2004.

RIO DE JANEIRO. Decreto no 43.316, de 25 de novembro de 2011. Disciplina o exercício de encargos em ações formativas e demais atividades de ensino desenvolvidas pelas instituições de ensino de segurança pública do estado do Rio de Janeiro e dá outras providências. Rio de Janeiro, RJ, 2011. Disponível em: $<$ https://bancodetalentos.seseg.rj.gov.br/legislations/decretos/Decreto_43.316_20 11.pdf>. Acesso em: 10/05/2016.

SSEVP/ SESEG (2012). Currículos para os Cursos de Formação Soldados - Cabos - Sargentos, de 2012. Rio de Janeiro, RJ, 2012a, 45 p. Disponível em: <http://download.rj.gov.br/documentos/10112/1045734/DLFE52905.pdf/curriculocfap.pdf>. Acesso em: 31/07/2016.

. Decreto $n^{\circ}$ 43.621, de 29 de maio de 2012. Altera e consolida, sem aumento de despesa, a estrutura organizacional da Secretaria de Estado de Segurança - SESEG, e dá outras providências. Rio de Janeiro, RJ, 2012b. Disponível em: <http://download.rj.gov.br/documentos/10112/1311108/DLFE56303.pdf/maio1.pdf>. Acesso em: 31/08/2016.

SOUZA, José dos Santos. A formação do trabalhador no contexto da reconfiguração do trabalho, da produção e dos mecanismos de mediação do conflito de classe. Revista Contemporânea de Educação, vol. 10, n. 20, p. 50-66, julho/dezembro de 2015.

Projeto Gerencialismo. Arquivo Mp4. UFRRJ,

GTPS, 2016a.

O que é gerencialismo. Nova Iguaçu (RJ):

GTPS/UFRRJ, 2016b. Disponível em: http://trabalhopoliticaesociedade.blogspot.com.br/2016/10/o-que-e-gerencialismo. html, acesso em 12/03/2017. 
VEIGA, Célia C. P. S. Reforma Administrativa do Estado, segurança pública e Formação de Soldados da PMERJ. Nova Iguaçu (RJ): 2016. 360 f. Dissertação (Mestrado em Educação) - Programa de Pós-graduação em Educação, Contextos Contemporâneos e Demandas Populares, Universidade Federal Rural do Rio de Janeiro (UFRRJ), Seropédica.

Recebido em: 20 de outubro de 2017. Aprovado em: 10 de março de 2018. Publicado em: 13 de junho de 2018. 